\title{
The Barthel index-dyspnea: a new two-dimensional dyspnea scale
}

This article was published in the following Dove Press journal:

International Journal of COPD

3 August 2016

Number of times this article has been viewed

\author{
Ming-Lung Chuangl-3
}

'Division of Pulmonary Medicine, Department of Internal Medicine, ${ }^{2}$ Department of Critical Care Medicine, Chung Shan Medical University Hospital, ${ }^{3}$ School of Medicine, Chung Shan Medical University, Taichung, Taiwan,

Republic of China
Correspondence: Ming-Lung Chuang Division of Pulmonary Medicine and Department of Critical Care Medicine, Chung Shan Medical University Hospital, No I I0,

Section I, Chien-Kuo North Road, South District, Taichung 4020I,

Taiwan, Republic of China

Tel +886 424739595 ext 347I8

Fax +886 424739220

Email yuan1007@ms36.hinet.net

\section{Dear editor}

Clinical evaluation tools have been widely used in assessing the baseline status, treatment response, and prognosis for patients with chronic respiratory diseases and mostly for patients with chronic obstructive pulmonary disease (COPD). ${ }^{1}$ By factor analysis, multiple domains of disease entities involve dyspnea, psychological status, health-related quality of life, and sensation or perception of dyspnea, ${ }^{2}$ wherein dyspnea is commonly evaluated by dyspnea scales such as Medical Research Council (MRC), Baseline Dyspnea Index, Oxygen-Cost Diagram, St George Respiratory Questionnaire activity domain, and Chronic Respiratory Disease Questionnaire dyspnea domain (CRQ-dyspnea). ${ }^{2}$ These scales describe the subjects' capability to perform at various levels of motor activity or functional status influenced or even limited by dyspnea. Indeed, exercise capacity is quantified; however, dyspnea is not. In our experience, the exertional dyspnea scales had better correlations with exercise performances $(|r|=0.29-0.65)$ than dyspnea sensation intensity $(|r|=0.06-0.55)$ and better correlation with walking $(|r|=0.5-0.65)$ than peak exercise $(|r|=0.29-0.39)$.

Recently, Vitacca et al addressed daily activities and dyspnea sensation intensity simultaneously in exertional dyspnea scale. ${ }^{3}$ They have successfully developed a new dyspnea scale by integrating ten daily life activities of Barthel index and five categories of dyspnea sensation intensity. ${ }^{3}$ The new scale was reported to be reliable, sensitive, and adequate as a tool for measuring the level of dyspnea while performing daily life activities and the responsiveness after treatment.

The new dyspnea scale is two-dimensional and conceptually agrees with multidimensional dyspnea profile. ${ }^{4}$ There are some similarities between the Barthel index-dyspnea and the CRQ-dyspnea, ${ }^{5}$ which was not discussed in Vitacca's report. The CRQ-dyspnea encompasses five items regarding exertional dyspnea part that the subject experienced during the last 2 weeks. The five items regarding activities of 26 listed activities in which the patient experiences dyspnea during day-to-day activities were selected by the research subjects as they considered these were the most important activities. The subject indicated the degree of dyspnea from grade 1 (extremely short of breath) to grade 7 (not at all short of breath) he or she had had. The five activity items were selected by the subjects' own volition, thereby being their most important activities but varying from one subject to another. In contrast, the ten daily activities of Barthel index are listed as a format, thereby probably some selected items not being their important activities but being more consistent in the subjects' daily activities during follow-up. Barthel index-dyspnea and CRQ-dyspnea scales 
simultaneously use categories to describe dyspnea sensation intensity, although the categories are different.

In Vitacca's report, Barthel index-dyspnea has strong concurrent validity with 6-minute walk test and MRC. Since 6-minute walk test and MRC are a submaximum exercise test and exercise capacity oriented scale, respectively, comparison of the utility of Barthel index-dyspnea scale with CRQ-dyspnea scale or with other quality of life questionnaires is enthusiastically anticipated in the future study. Additionally, the exercise intensity of daily activity of Barthel index is very mild-to-mild. This might be hard to extrapolate Barthel index-dyspnea scale to the subjects who have mild severity in chronic respiratory diseases as only $8.1 \%$ of study population were mild COPD in their study. Finally, magnitude of uncertainty was not quantified in Vitacca's report. Providing the confidence interval of correlation coefficient would be helpful for the readers.

\section{Disclosure}

The author reports no conflicts of interest in this communication.

\section{References}

1. Parshall MB, Schwartzstein RM, Adams L, et al. An official American Thoracic Society statement: update on the mechanisms, assessment, and management of dyspnea. Am J Respir Crit Care Med. 2012;185(4): 435-452.

2. Hajiro T, Nishimura K, Tsukino M, Ikeda A, Koyama H, Izumi T. Analysis of clinical methods used to evaluate dyspnea in patients with chronic obstructive pulmonary disease. Am J Respir Crit Care Med. 1998;158(4): 1185-1189.

3. Vitacca M, Paneroni M, Baiardi P, et al. Development of a Barthel Index based on dyspnea for patients with respiratory diseases. Int J Chron Obstruct Pulmon Dis. 2016;11:1199-1206.

4. Meek PM, Banzett R, Parshall MB, Gracely RH, Schwartzstein RM, Lansing R. Reliability and validity of the multidimensional dyspnea profile. Chest. 2012;141(6):1546-1553.

5. Guyatt GH, Berman LB, Townsend M, Pugsley SO, Chambers LW. A measure of quality of life for clinical trials in chronic lung disease. Thorax. 1987;42(10):773-778.

Dove Medical Press encourages responsible, free and frank academic debate. The content of the International Journal of Chronic Obstructive Pulmonary Disease 'letters to the editor' section does not necessarily represent the views of Dove Medical Press, its officers, agents, employees, related entities or the International Journal of Chronic Obstructive Pulmonary Disease editors. While all reasonable steps have been taken to confirm the content of each letter, Dove Medical Press accepts no liability in respect of the content of any letter, nor is it responsible for the content and accuracy of any letter to the editor.

\section{Publish your work in this journal}

The International Journal of COPD is an international, peer-reviewed journal of therapeutics and pharmacology focusing on concise rapid reporting of clinical studies and reviews in COPD. Special focus is given to the pathophysiological processes underlying the disease, intervention programs, patient focused education, and self management protocols.

\section{Dovepress}

This journal is indexed on PubMed Central, MedLine and CAS. The manuscript management system is completely online and includes a very quick and fair peer-review system, which is all easy to use. Visit $\mathrm{http} / / / \mathrm{www}$.dovepress.com/testimonials.php to read real quotes from published authors. 